УДК 618.4:616.127-005.8

АКУШЕРСКАЯ ТАКТИКА ПРИ ИНФАРКТЕ МИОКАРДА ВО ВРЕМЯ БЕРЕМЕННОСТИ (КЛИНИЧЕСКИЙ СЛУЧАЙ)

DOI: $10.31618 /$ ESU.2413-9335.2019.1.67.339

Протопопова Н.В. ${ }^{1,2}$, Дудакова В.Н. ${ }^{1}$, Каретников И.А. ${ }^{1,2}$, Бородашкин В.В. ${ }^{2}$

${ }^{1}$ Кафедра перинатальной и репродуктивной медицинь ИГМАПО - филиал ГБОУ ДПО РМАНПО Министерства Здравоохранения РФ, (664079, Иркутск, м/р. Юбилейный, 100, Россия) ${ }^{2}$ ГБУЗ Иркутская ордена «Знак Почета» областная клиническая больница Областной перинатальный иентр

(664079, Иркутск, м/р. Юбилейный, 100, Россия)

\title{
OBSTETRIC TACTICS IN MYOCARDIAL INFARCTION DURING PREGNANCY
}

Protopopova N.V. ${ }^{12}$, Dudakova V.N. ${ }^{1}$, Karetnikov I.A. ${ }^{2}$, Borodashkin V.V. ${ }^{2}$ I"Russian Medical Academy of Continuous Professional Education" of RF Ministry of Healthcare (664079, Irkutsk, 100, Yubileiny mkr., Russian Federation)

${ }^{2}$ Irkutsk Regional Clinical Hospital, Regional Perinatal Center (664079, Irkutsk, 100, Yubileiny mkr., Russian Federation)

\section{РЕЗЮМЕ}

Представлен клинический случай инфаркта миокарда в 36 недель беременности у беременной с экстрагенитальной патологией. Рассмотрена возможность консервативного лечения и пролонгирования беременности с благополучным родоразрешением путем операции кесарева сечения в доношенном сроке беременности.

\section{ABSTRACT}

Presents a clinical case Patient YA., 33 years old, who underwent myocardial infarction in 36 weeks of pregnancy with aretrial hypertension and obesity. The possibility of conservative treatment and prolongation of pregnancy with successful delivery by cesarean section in the term of pregnancy is considered.

Ключевые слова: инфаркт миокарда и беременность, артериальная гипертензия, факторы риска инфаркта миокарда, диагностика инфаркта миокарда

Keywords: myocardial infarction and pregnancy, arterial hypertension, risk factors for myocardial infarction, diagnosis of myocardial infarction

Сердечно-сосудистые заболевания попрежнему остаются одной из главных причин материнской смертности. Среди них особого внимания заслуживают такие жизнеугрожающие события, как инсульт и инфаркт миокарда. Риск инфаркта миокарда во время беременности чаще встречается у многорожавших женщин и увеличивается с возрастом [2,3]. В возрасте 30-34 года встречается с частотой 8,8 на 100000 родов; в 40 лет и старше 30,2 на 100000 родов [2,3]. Частота острого инфаркта миокарда оценивается от 0,6 до 1 случая на 10000 беременностей $[1,2,3]$, летальность отмечается в $5,1 \%-37 \%$ случаев $[2,3,4]$. Инфаркт миокарда во время беременности чаще встречается в третьем триместре, ишемия миокарда развивается наиболее часто в передней стенке сердца [2].

В настоящее время прослеживается тенденция к увеличению числа женщин старшей возрастной группы, планирующих беременность. За последние 20 лет количество беременных в возрасте старше 40 лет увеличилось в 2 раза. Наиболее распространенными проблемами в этой группе беременных являются ожирение, нарушение липидного обмена, сахарный диабет, артериальная гипертензия, курение.

Основные факторы риска инфаркта миокарда при беременности не отличаются от наблюдаемых в общей популяции: семейный анамнез атеросклеротической болезни, дислипидемия, сахарный диабет, курение, применение комбинированных оральных контрацептивов. Кроме факторов риска в общей популяции выделяют индуцированные факторы риска острого инфаркта миокарда у беременных:

•гипертензия - OR 11,7 (6,9-21,2) p<0,01

-тромбофилия - OR 22,3 (8,2-61,1) p < 0,01

-анемия - OR 2,0 (1,3-3,2) p<0,01

-диабет - OR 3,2 (1,5-6,9) $\mathrm{p}<0,01$

-мигрень - OR 4,2 (1,0-17,1) p<0,05

•курение - OR 6,2(4,1-9,5) p<0,05.

Пациентки с высоким риском развития ишемической болезни сердца должны быть обследованы на этапе планирования беременности.

Диагностика инфаркта миокарда у беременных представляет серьезные трудности, хотя иногда типичная клиническая картина, наличие в анамнезе приступов стенокардии, характерные изменения ЭКГ позволяют распознать это заболевание. Диагностические критерии острого коронарного синдрома у беременных в большинстве случаев общепринятым: болевой синдром в грудной клетке, изменения ЭКГ и наличие биохимических маркеров некрозам миокарда.

Клинический случай.

Пациентка Я., 33 лет, первобеременная наблюдалась в женской консультации с 8 недель 
беременности. В анамнезе - бесплодие 10 лет эндокринного генеза. Вредные привычки - курение больше 10 сигарет в день. В 11 недель госпитализирована в терапевтическое отделение с DS: Нейроциркуляторная дистония. Соматическая патология: ожирение II степени - ИМТ - 34,7. С 13 недель уточнен диагноз артериальная гипертензия 2 степени, риск 3, начата гипотензивная терапия допегит 1000мг/сутки. В 27 недель ухудшение состояния, госпитализирована в отделение неотложной кардиологии, где впервые при беременности была диагностирована ишемическая болезнь сердца, вазоспастическая стенокардия. Проведена смена гипотензивной терапии нифекард $30 \mathrm{M \Gamma} * 2$ раза в сутки, добавлен кардиомагнил 75мг. С 28 недель гестации было рекомендовано ограничение физической нагрузки, предотвращение стрессов. Пациентка наблюдалась акушером-гинекологом, терапевтом, кардиологом. С 31 недели доза нифекарда увеличена до 90мг/сутки, АД на цифрах 140/90*130/80 мм рт ст, с этого же срока уточнен диагноз - гестационный сахарный диабет..

Из анамнеза: 27.05.2016 появились давящие боли за грудиной, которые в течение двух суток рецидивировали. 29.05.2016 боли усилились, что послужило поводом для вызова скорой медицинской помощи, которая доставила беременную в ОПЦ ГБУЗ ИОКБ. В областном перинатальном центре, учитывая боли за грудиной, проведена ЭКГ и пациентка была переведена в отделение анестезиологии и реаниматологии №8 ГБУЗ ИОКБ с DS: Ишемическая болезнь сердца, инфаркт передне-перегородочно-боковой области левого желудочка, ХCH 2А, ФК 2, Killip 1, гипертоническая болезнь 3 стадии, риск 4 (ИБС, курение), Беременность 36 недель.

Объективно: состояние тяжелое, тяжесть обусловлена коронарной недостаточностью, острым инфарктом миокарда. Кожные покровы бледно-родового цвета, периферических отеков нет. Дыхание везикулярное, хрипов, частота дыхательных движений в 18 в минуту, сатурация кислорода 95\%. Тоны сердца приглушенны, ритмичны, АД 99/65 мм рт ст, ЧСС 102 удара в минуту. По данным ЭКГ - Q инфаркт переднеперегородочной-боковой области левого желудочка, формирование (-) Е в V1-V6. Эхокардиография - гипокинез передней, переднебоковой , перегородочной стенок во всех сегментах, акинез с дискинезом. Функциональный выброс (ФВ) (Т) 42\%, ФВ (S) 27\%, толщина миокарда левого желудочка в верхушке 0,5cм, плоская аневризма верхушки миокарда левого желудочка. Матка соответствует сроку беременности, матка в нормотонусе, сердцебиение плода ритмичное, 140 ударов в минуту. По КТГ НСТ реактивный.

Катетеризация сердца в данном случае не проводилась, в связи с диагностической информативностью ЭКГ и ЭХОКГ, беременностью. Согласно данным литературы в исследовании 859 случаев острого инфаркта миокарда во время беременности только 45\% пациенток подвергались катетеризации сердца.

Диагноз острого инфаркта миокарда у беременных подтверждается изменений уровней сердечных ферментов. Лабораторные исследования подтвердили острый инфаркт миокарда: троп-тест 0,37microg/l, креатинкиназа $334 \mathrm{ME} / л$, КК-МВ 29,3МЕ/л, липидограмма - холестерин 7,6 ммоль/л, триглицериды 8,6 ммоль/л, липопопротеины высокой плотности 1,0 ммоль/л, липопротеины низкой плотности 2,7 ммоль/л, липопротеины очень низкой плотности 3,9 ммоль/л. В общем анализе крови лейкоциты $14,9 * 10^{9}$, эритроциты $3,47 * 10^{12}$, гемоглобин 98г/л, гематокрит $32,9 \%$, тромбоциты $353 * 10^{9}$, коагулограмма -MНО 1,08, АЧТВ - 29,5сек, фибриноген 5,18г/л, ПТВ 12,9сек, ПТИ 93\%. Учитывая отсутствие ангиозных болей, по ЭКГ - подострый период инфаркта миокарда, беременность 36 недель - проводилась консервативная терапия инфаркта миокарда (антикоагулянты и b-блокаторы). Проводился междисциплинарный подход к наблюдению и лечению, пациентка наблюдалась в отделении реанимации и интенсивной терапии, где обеспечивался непрерывный мониторинг состояния матери и плода с участием врачей анестезиолога, кардиолога, акушера-гинеколога. Определена тактика ведения беременной с консервативным лечением в течение 2 недель и последующим оперативным родоразрешением в 38 недель. Беременной был назначен гепарин 1тысЕД/час, бисопролол 5мг. Гепарин не проникает через плаценту и является препаратом выбора во время беременности. Салицилаты не назначались, так как проникают через плаценту и поступают в кровоток плода, вызывая ряд осложнений: антенатальная гибель плода, развитие салицилат интоксикации плода, ацидоз у новорожденных кровотечение преждевременное закрытие артериального протока. Имеется значительный опыт лечения беременных bблокаторами, показана безопасность применения нифедипина. В течение 7 суток лечения в отделении анестезиологии и реаниматологии на фоне проводимого консервативного лечения (гепарин 1тысЕД/час под контролем АЧТВ, бисопролол 5мг, омепразол 20мг), состояние пациентки было стабильно тяжелым. Ангиозные боли не рецидивировали, гемодинамика была стабильной, по ЭКГ - закономерная динамика Qинфаркта левого желудочка. Состояние плода по данным КТГ, допплерометрии оставалось сохранным.

06.06.2016 состояние пациентки резко ухудшилось, появились рецидивирующие ангиозные боли, нестабильность гемодинамики, по ЭКГ - признаки рецидива инфаркта миокарда. По данным эхокардиографии зарегистрирована отрицательная динамика в отношении размера левого желудочка и функционального выброса, увеличилась зона диссинергии и ее степень. Проведен консилиум и принято решение о проведении экстренной диагностической 
коронарографии - выявлен окклюзивный тромбоз среднего сегмента передней нисходящей артерии, формирующиеся внутрисосудистые коллатерали. Проведенное обследование требовало проведение рентгеноэндоваскулярной дилятации и стентирования передней нисходящей артерии. Принято решение о проведении экстренного оперативного родоразрешения. Показания к экстренному родоразрешению - рецидивирование инфаркта миокарда, необходимость проведения эндоваскулярных методов лечения с назначением двойной антиагрегантной терапией. 06.06.2016 выполнено экстренное родоразрешение путем операции кесарева сечения на фоне общей эндотрахеальной анестезии. В головном предлежании извлечена девочка 2530гр, длиной 48 см с оценкой по шкале Апгар 7/8 баллов. После родоразрешения продолжилась искусственная вентиляция легких, инотропная поддержка адреналин 0,1 мкг/кг/мин, дофамин 5мкг/кг/мин.

$$
07.06 .2016
$$

рентгеноэндоваскулярная проведена дилатация транслюминальная баллонная ангиопластика, стентирование коронарных артерий. С 10 по 12 июня 2016 года инфузия левосимендана 0,1мкг/кг/мин. По эхокардиографии от 12.06.2016 ФВ (Т) - 50\%, ФВ (S) - 38\%. Зоны диссинергии: гипокинез верхушки, передней и перегородочной стенок в верхушечном и среднем сегменте.

14 июня 2016 года пациентка переведена в кардиологическое отделение и 29 июня в удовлетворительном состоянии выписана с ребенком домой.

Согласно данным литературы реваскуляризация является важным этапом лечения острого инфаркта миокарда. Нет исследований, сравнивающих чрескожное коронарное вмешательство с тромболизисом у беременных. Каждый случай должен оцениваться индивидуально, чтобы определить наиболее подходящий метод лечения.

Клинический опыт применения тромболитической терапии у беременных ограничен. Тромболизис не рекомендуется, если установлено коронарное расслоение, при предлежании плаценты, врастании плаценты и близко к сроку родов [7].

Аортокоронарное шунтирование может проводиться при беременности. Хирургическое вмешательство следует осуществлять в начале второго триместра, после периода органогенеза $[5,6,7]$. Если срок гестации более 28 недель, необходимо на первом этапе проведение кесарева сечения с последующей операцией на сердце [8].

Заключение: чаще всего инфаркт миокарда развивается в третьем триместре у женщин старше
33 лет с классическими факторами риска: курение, гиперлипидемия, ожирение, артериальная гипертензия. В случае острого инфаркта миокарда родоразрешение следует отложить на 2 более недели с момента инфаркта миокарда [2,4]. Ведение пациенток с инфарктом миокарда и беременностью требует междисциплинарного подхода с участием лечащих врачей: акушерагинеколога, кардиолога, анестезиологареаниматолога. Следует разработать план для чрезвычайного родоразрешения потенциально жизнеспособного плода в случае внезапного ухудшения материнского состояния. Беременной должна оказываться медицинская помощь в отделении интенсивной терапии многопрофильного стационара с возможностью проведения коронарографии, ангиопластики, аортокоронарного шунтирования. При отказе пациентки от стерилизации необходимо выбрать надежный метод контрацепции (возможно применение пролонгированных гестагенов, внутриматочной рилизинг-системы).

Предыдущий инфаркт миокарда не является абсолютным противопоказанием для последующей беременности, но потенциально пациентки подвержены риску ишемии и дисфункции левого желудочка. Следует проводить обследование перед планируемой беременностью, включающее электрокардиографию, стресс- эхокардиографию и оценку кровотока в коронарных артериях.

\section{Литература / References}

1.Burlew BS. Managing the pregnant patient with heart disease. Clin Cardiol. 1990;13:757-62.

2.Roth A, Elkayam U. Acute myocardial infarction associated with pregnancy. Ann Intern Med.1996;125:751-62.

3.James AH, Jamison MG, Biswas MS, Brancazio LR, Swamy GK, Myers ER. Acute myocardial infarction in pregnancy: A United States population-based study. Circulation 2006;113:156471.

4.Hankins GD, Wendel GD, Jr. Leveno KJ, Stoneham J. Myocardial infarction during pregnancy: A review. Obstet Gynecol. 1985;65:139-46.

5.Wilson AM, Boyle AJ. Fox P. Management of ischaemic heart disease in women of child-bearing age. Intern Med J. 2004;34:694-7.

6.Chambers CE, Clark SL. Cardiac surgery during pregnancy. Clin Obstet Gynecol. 1994:37:316-23.

7.Bernal JM, Miralles PJ. Cardiac surgery with cardiopulmonary bypass during pregnancy. Obstet Gynecol Surv. 1986:41:1-6.

8.Parry AJ, Westaby S. Cardiopulmonary bypass during pregnancy. Ann Thorac Surg. 1996:61:1865-9. 